Review Article

\title{
Prevalence of Microorganisms of Public Health Significance in Ready-to-Eat Foods Sold in Developing Countries: Systematic Review and Meta-Analysis
}

\author{
Dechasa Adare Mengistu $(\mathbb{D}$ and Sina Temesgen Tolera \\ Department of Environmental Health, College of Health and Medical Science, Haramaya University, Harar, \\ PO. Box 235 Dire Dawa, Ethiopia \\ Correspondence should be addressed to Dechasa Adare Mengistu; dechasa.adare@haramaya.edu.et
}

Received 9 August 2020; Revised 17 September 2020; Accepted 19 October 2020; Published 2 November 2020

Academic Editor: Alejandro Castillo

Copyright ( 2020 Dechasa Adare Mengistu and Sina Temesgen Tolera. This is an open access article distributed under the Creative Commons Attribution License, which permits unrestricted use, distribution, and reproduction in any medium, provided the original work is properly cited.

\begin{abstract}
Background. The issue of microbial quality and safety of ready-to-eat foods has become a public health concern that needs to be addressed to protect the consumer's health. Contamination of ready-to-eat foods by enteric pathogens such as Escherichia coli, Salmonella, and Staphylococcus aureus bacteria is associated with potential health risks and can cause foodborne outbreaks. Thus, the systematic review and meta-analysis aimed at determining the overall evidence on the prevalence of microorganisms of public health significance in ready-to-eat foods based on previous studies. Methods. The articles published from 2015 to 2020 were searched from multiple electronic databases such as PubMed, Google Scholar, MEDLINE, CINAHL, Science Direct, Web of Science, and the Directory of Open Access Journals. The JBI critical appraisal tool was applied to the included articles. To determine the heterogeneity among the included articles, $I^{2}$ statistics were used while publication bias was evaluated using the visual funnel plot. A Forest plot using the random effect model for meta-analysis was used to estimate the pooled prevalence of $E$. coli, Salmonella, and S. aureus in ready to eat foods. Results. The pooled prevalence of E. coli, Salmonella, and S. aureus in ready to eat foods was 33.8\% (95\% CI: 19.9, 51.2; $Q$ value $\left.=67.080, I^{2}=89.56 \%\right), 26.0 \%\left(95 \%\right.$ CI: 13.8, 43.6\%; $Q$ value $\left.=83.67, I^{2}=91.63 \%\right)$, and $46.3 \%$ (95\% CI: 24.8, 69.4\%, $I^{2}=94.9 \%$ ), respectively. Conclusion. The findings show that contamination of ready-to-eat foods with pathogenic microorganisms continues to be a public health risk. Thus, effective food hygiene and safety systems are necessary to protect the health of the consumers and the public as a whole.
\end{abstract}

\section{Background}

Ready-to-eat foods (RTF) are defined as foods being ready for consumption that could be raw or cooked, hot, or chilled and can be consumed without further treatment or any processing $[1,2]$. The consumption of various types of ready-to-eat foods in public places has become common worldwide. Due to the vital role of foods in human existence, it is important to maintain food safety to ensure that human being is safe from foodborne diseases or other related health hazards [3].

Ready-to-eat foods play a vital role in meeting the food requirements of many inhabitants and being appreciated by consumers for their affordability, accessibility, variety, and unique organoleptic properties [4-6]. However, unless they are handled under hygienic conditions and safety, ready-toeat foods can serve as a good medium for the growth and multiplication of various pathogenic microorganisms of public health concern. The World Health Organization estimated more than 200 various types of diseases or illnesses caused or spread by foods [7]. However, the most common foodborne pathogen includes but is not limited to Bacillus cereus, Clostridium botulinum, Escherichia coli, Shigella spp., Salmonella spp., Staphylococcus aureus, and Campylobacter [8].

Currently, the incidence of foodborne illness involving a broad range of diseases caused by pathogenic microorganisms is rising worldwide and becomes a public health concern 
$[9,10]$. And foodborne illnesses are an important challenge to public health and cause a significant economic problem in many countries [11]. In developed countries, an estimated one-third of the population is affected by foodborne diseases each year. However, foodborne diseases are common and leading causes of illness in developing countries because of the prevailing poor hygienic and sanitation conditions or practices, weak food safety and regulatory systems, lack of resources, and lack of education [12, 13]. In response to these problems, health and other concerned organizations are increasing their effort to improve the quality and safety of foods and to prevent foodborne disease [14]. Thus, it is essential to provide the overall evidence on the prevalence of microorganisms of public health concern in ready-to-eat foods.

\section{Objective}

The study aimed to systematically review and provide the overall current evidence on the prevalence of microorganisms of public health concerns in ready-to-eat foods in developing countries.

\section{Method}

This systematic review and meta-analysis was conducted under the Preferred Reporting Items for Systematic Reviews and Meta-Analysis (PRISMA) guidelines [15].

3.1. Eligibility Criteria. The articles that met the following inclusion criteria were included in the systematic review and meta-analysis:

(i) Study Area. Research articles conducted in developing countries.

(ii) Study Design. Cross-sectional studies reported the prevalence of microorganisms of public health concern in ready-to-eat foods such as Salmonella, $S$. aureus, and E. coli.

(iii) Language. Full-text articles published in the English language.

(iv) Population. Articles conducted on any type of readyto-eat foods in developing countries.

(v) Publication Issue. Primary research articles published in peer-reviewed journals from 2015 to 2020.

3.2. Outcome Measure. The outcome of this systematic review and meta-analysis is to determine the pooled prevalence of Escherichia coli, Salmonella, and Staphylococcus aureus in ready-to-eat foods in developing countries. The prevalence of selected microorganisms was calculated by dividing the number of positive ready-to-eat foods samples to the total number of ready-to-eat foods samples investigated or analyzed (total sample size) multiplied by 100 .

3.3. Information Sources and Search Strategy. The articles published from 2015 to 2020 were identified through a literature search of electronic databases such as Google Scholar,
PubMed, MEDLINE, CINAHL, Science Direct, Web of Science, and the Directory of Open Access Journals. From PubMed databases, articles were searched using a combination of Boolean logic operators (AND, OR, and NOT), Medical Subject Headings (MeSH), and keywords. The searches were done using the keywords and Boolean logic operators as following: (Prevalence* OR Occurrence* OR frequency* OR Contamination) AND (Microorganisms* OR Bacterial* OR Microbial* OR foodborne pathogens) AND (Public* OR Health* OR Public health) AND (significance* OR concern* OR hazards* OR risk) AND (ready to eat* OR street * OR fast* OR cooked* OR processed* OR prepared* OR packed) AND (foods* OR meal* OR meat* OR fruit* OR fruit products * ${ }^{*} \mathrm{OR}$ dairy product* $\mathrm{OR}$ vegetable ${ }^{*} \mathrm{OR}$ vegetable products, etc..) AND (Sub-Saharan * OR Developing* OR low income * OR middle income) AND (Countries* OR * OR region, Africa, etc.).

The identified keywords and index terms were checked by authors (Mengistu DA and Tolera ST) across the included electronic databases. Additionally, manual searching for further studies was done by authors (Mengistu DA and Tolera ST) to cover other published articles. The last search was done on April 20, 2020.

3.4. Study Selection. Duplicated studies were removed using the ENDNOTE software version X5 (Thomson Reuters, USA). The authors (Mengistu DA and Tolera ST) individually screened all identified articles based on their titles and abstracts by applying the eligibility criteria. Disagreements were solved by taking the mean score of the two reviewers (Mengistu DA and Tolera ST) after discussing the rationale on differences and repeating the review procedure.

3.5. Data Extraction. All required and relevant data were extracted from the included articles using a predetermined data abstraction form by authors (Mengistu DA and Tolera ST) independently. The extracted data include the name of the authors, sample size, the primary outcome (prevalence of selected microorganisms of public health significance), countries where the article was carried out, year of publication, and study design.

3.6. Quality Assessment. For articles met inclusion criteria, abstracts were checked to establish their relevance for the study. The quality of the included articles was assessed using independent appraisal tools (JBI Critical Appraisal tools) [16]. Then, the score was taken across all the studies and graded as high ( $75 \%$ and above score), moderate (50-75\% score), and low ( $<50 \%$ score) quality. High quality in this work indicates a low risk of bias. Disagreements made among authors (Mengistu DA and Tolera ST) on what is to be extracted were solved by discussion. Finally, the authors found all articles with a low risk of bias.

3.7. Statistical Procedure. The required data were extracted using a Microsoft Excel format, 2016. After the extraction, the data were imported to the Comprehensive MetaAnalysis (CMA) V3 statistical package (software). Then, the characteristics of the original articles were described using texts, tables, and forest plots. Heterogeneity among 


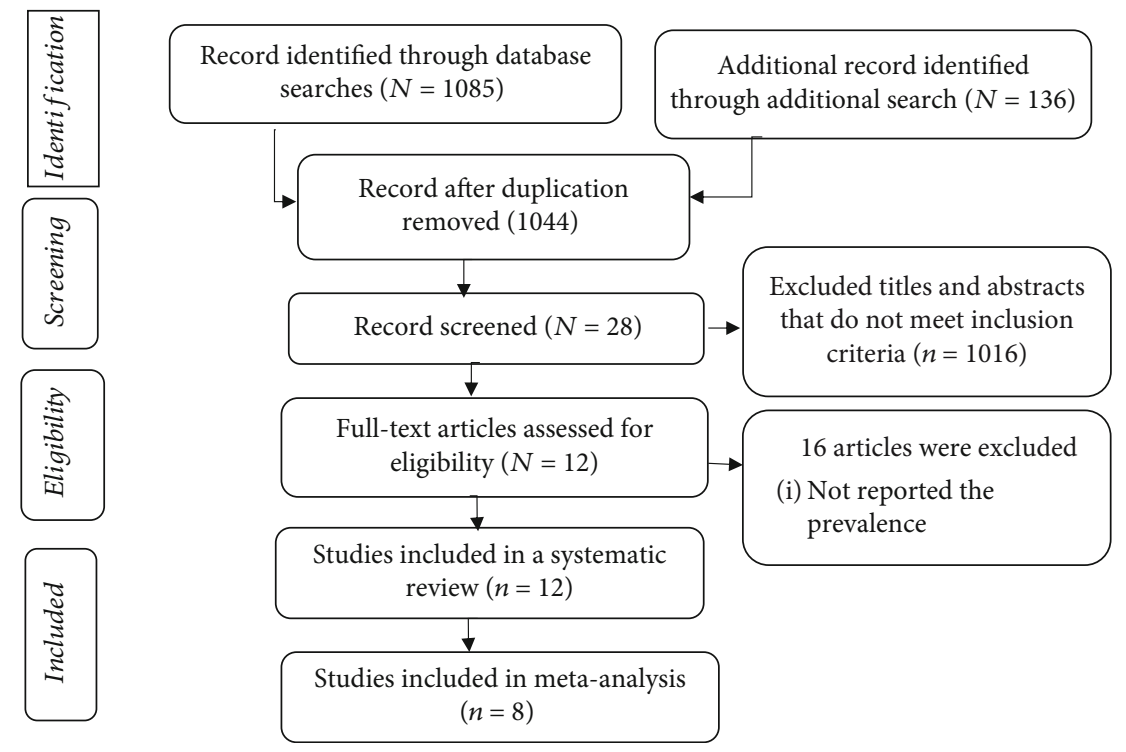

FIGURE 1: PRISMA flow diagram indicating the selection process of included articles for a systematic review and meta-analysis, 2020.

the reported prevalence was checked by using a heterogeneity $I^{2}$ test.

The random-effect model of meta-analysis and forest plot was used to estimate the pooled prevalence of microorganisms of public health concern in ready-to-eat foods with $95 \%$ confidence intervals. The possibility of publication bias was assessed by visual funnel plots, and a $p$ value of $<0.05$ was considered as the evidence for publication bias. Moreover, subgroup analysis was done based on the countries where the included articles were conducted and publication year to minimize the random variations (heterogeneity) between the point estimates of the included articles.

\section{Result}

4.1. Study Selection. A total of 1221 articles published from 2012 to 2020 were identified using electronic databases and hand searching. After an initial screening of articles by their titles and abstracts, 149 duplicate articles were excluded, while 1044 studies were excluded based on the predetermined inclusion and exclusion criteria. Then, the full texts of the remaining 28 articles were further assessed to determine their eligibility for the systematic review and metaanalysis. Additionally, 16 articles were excluded as they failed to report the prevalence of selected microorganisms of public health concern. Twelve original articles that meet the predetermined inclusion criteria were included in the systematic review, of which 8 articles were included in quantitative analysis (meta-analysis) (Figure 1).

4.2. Study Characteristics. In this study, a total of 625 readyto-eat food samples were included in eight articles published from 2015 to 2020 that were conducted in seven different developing countries: one in Ethiopia, two in Nigeria, one in India, one in Pakistan, one in Sudan, one in Namibia, and one in South Africa. All the included articles were cross-sectional studies with a sample size ranging from 15 to 205 ready-to-eat foods. In addition, based on JBI Critical Appraisal tool [16], all the included articles had a low risk of bias (Table 1).

The prevalence of E. coli, Salmonella, and S. aureus in ready-to-eat foods was in the range of $1.8 \%$ (24) to $100 \%$ (21), $2.0 \%$ (19) to $73.3 \%(21)$, and $7.0 \%(22)$ to $100 \%(21)$, respectively (Table 1). Overall, about 172 (27.5\%), 168 (26.9\%), and 259 (41.4\%) of ready-to-eat food samples investigated in eight articles were contaminated with Salmonella, E. coli, and S. aureus, respectively.

\subsection{Data Synthesis and Statistical Analysis}

4.3.1. Prevalence of Microorganisms of Public Health Concerns in Ready-to-Eat Foods. We conducted a metaanalysis using the Comprehensive Meta-Analysis (CMA) V3 statistical package to determine the pooled prevalence of microorganisms of public health concern in ready-to-eat foods.

(1) Prevalence of E. Coli. The pooled prevalence of Escherichia coli in ready-to-eat foods of developing countries was found to be $33.8 \%$ (95\% CI: 19.9, 51.2; $Q$ value $=67.080$, $I^{2}=89.56 \%$ ) (Figure 2).

Based on a subgroup analysis of included articles by country, the lowest prevalence [1.8\% (95\% CI: $0.7 \%, 4.9 \%)$ with a $p$ value of $<0.001]$ of $E$. coli in ready-to-eat foods was observed in South Africa whereas the highest prevalence [88.8\%, (95\% CI: 62.5-97.40\%) with a $p$ value of 0.009] of E.coli in ready-to-eat foods was observed among the studies conducted in Nigeria.

However, after subgroup analysis by country, the overall pooled prevalence of $E$. coli in ready-to-eat foods was $[34.0 \%$ (95\% CI: 29.6-38.7\%) with a $p$ value of $<0.001$ ] (Figure 3).

Regarding the publication year, the pooled prevalence of E. coli was higher [75.1\% (95\% CI: 22.2-97.0\%)] among the studies published in 2016, while the article published 
TABLE 1: Overall characteristics of included articles in systematic review and meta-analysis, 2020.

\begin{tabular}{|c|c|c|c|c|c|c|c|c|c|}
\hline \multirow[t]{2}{*}{ Authors } & \multirow{2}{*}{$\begin{array}{c}\text { Publication } \\
\text { Year }\end{array}$} & \multirow[t]{2}{*}{$N$} & \multirow[t]{2}{*}{ Study design } & \multicolumn{3}{|c|}{$\begin{array}{l}\text { Prevalence of selected } \\
\text { microorganisms }\end{array}$} & \multirow[t]{2}{*}{ Country } & \multirow[t]{2}{*}{ Risk of bias } & \multirow[t]{2}{*}{ References } \\
\hline & & & & E. coli & Salmonella & S. aureus & & & \\
\hline Temesgen et al. & 2016 & 71 & Cross-sectional & $29.6 \%$ & $12.7 \%$ & $9.9 \%$ & Ethiopia & Low & {$[17]$} \\
\hline Reddi et al. & 2015 & 150 & Cross-sectional & $42.6 \%$ & $48.6 \%$ & $73.3 \%$ & India & Low & {$[18]$} \\
\hline Asghar et al. & 2018 & 40 & Cross-sectional & $30 \%$ & $2.0 \%$ & $70.0 \%$ & Pakistan & Low & [19] \\
\hline Elhag et al. & 2015 & 30 & Cross-sectional & $26.7 \%$ & $13.3 \%$ & $55 \%$ & Sudan & Low & {$[20]$} \\
\hline Ire and Imuh & 2016 & 15 & Cross-sectional & $100 \%$ & $73.3 \%$ & $100 \%$ & Nigeria & Low & {$[21]$} \\
\hline Shiningeni et al. & 2019 & 96 & Cross-sectional & $35.0 \%$ & $11.0 \%$ & $7.0 \%$ & Namibia & Low & {$[22]$} \\
\hline Okechukwu et al. & 2016 & 17 & Cross-sectional & $83.3 \%$ & $66.7 \%$ & $66.7 \%$ & Nigeria & Low & {$[23]$} \\
\hline Asiegbu et al. & 2020 & 205 & Cross-sectional & $1.8 \%$ & $21.8 \%$ & $31.8 \%$ & South Africa & Low & {$[24]$} \\
\hline
\end{tabular}

N: sample size; E. coli: Escherichia Coli; S. aureus: Staphylococcus aureus.

\begin{tabular}{|c|c|c|c|c|c|c|c|c|c|c|}
\hline \multirow[b]{2}{*}{ Study name } & \multicolumn{5}{|c|}{ Statistics for each study } & & \multicolumn{4}{|c|}{ Event rate and 95\% CI } \\
\hline & $\begin{array}{c}\text { Event } \\
\text { rate }\end{array}$ & $\begin{array}{l}\text { Lower } \\
\text { limit }\end{array}$ & $\begin{array}{l}\text { Upper } \\
\text { limit }\end{array}$ & Z-value & $\mathrm{p}$-value & & & & & \\
\hline Temesgen et al. & 0.296 & 0.202 & 0.412 & -3.333 & 0.001 & & & & & \\
\hline Reddi et al. & 0.426 & 0.349 & 0.506 & -1.806 & 0.071 & & & & & \\
\hline Asghar et al. & 0.300 & 0.179 & 0.457 & -2.456 & 0.014 & & & & & \\
\hline Elhag et al. & 0.267 & 0.140 & 0.450 & -2.447 & 0.014 & & & & & \\
\hline Ire and Imuh & 0.969 & 0.650 & 0.998 & 2.390 & 0.017 & & & & & \\
\hline Shiningeni et al. & 0.350 & 0.261 & 0.450 & -2.893 & 0.004 & & & & & \\
\hline Okechukwu et al. & 0.833 & 0.582 & 0.947 & 2.471 & 0.013 & & & & & \\
\hline \multirow[t]{2}{*}{ Asiegbu et al. } & 0.018 & 0.007 & 0.049 & -7.613 & 0.000 & & & & & \\
\hline & 0.338 & 0.199 & 0.512 & -1.828 & 0.068 & & & & & \\
\hline \multicolumn{6}{|c|}{$\begin{array}{l}\text { I squared }=89.565 \%, \mathrm{p} \text {-value }=0.000 \\
\text { Random model }\end{array}$} & -1.00 & -0.50 & 0.00 & 0.50 & 1.00 \\
\hline
\end{tabular}

FIgURE 2: Forest plot shows the pooled prevalence of E. coli in ready-to-eat foods in developing countries, 2020.

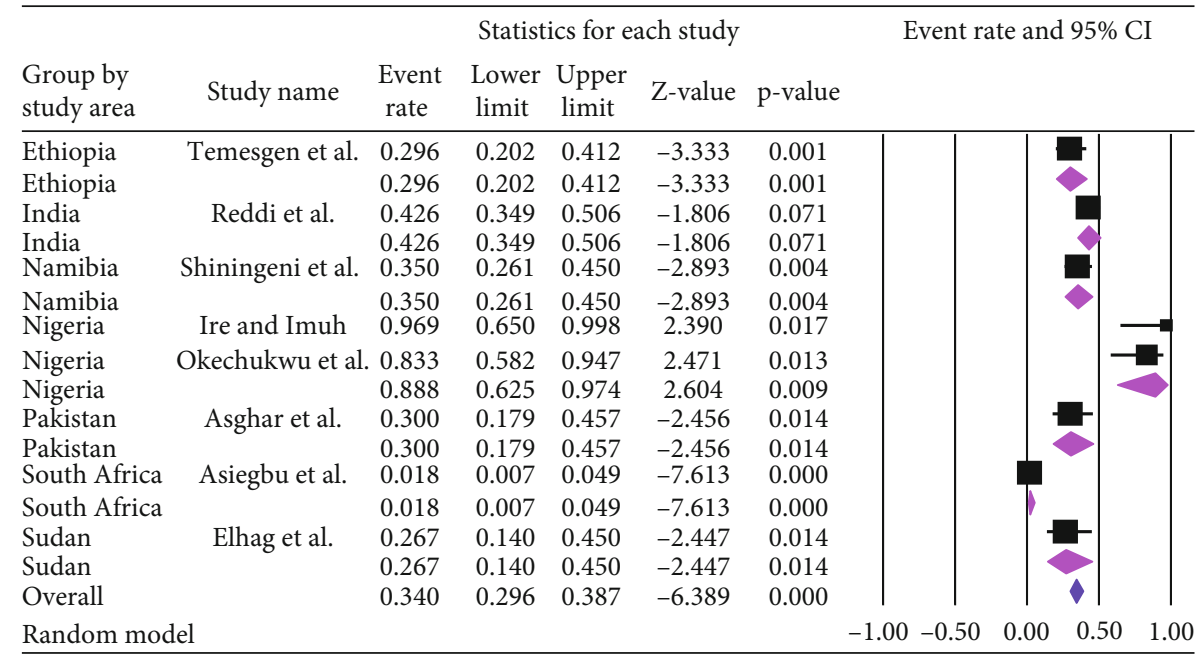

FIGURE 3: Subgroup analysis of the pooled prevalence of E. coli in ready-to-eat foods based on countries of developing countries, 2020.

in 2020 reported lower [1.8\% (95\% CI: $0.7 \%, 4.9 \%)$ with $p$ value of $<0.001$ ] prevalence (Figure 4).

(2) Prevalence of Salmonella. The pooled prevalence of Salmonella in ready-to-eat foods of developing countries was found to be $26.0 \%$ (95\% CI: 13.8, 43.6\%; $Q$ value $=$ $83.67, I^{2}=91.63 \%$ ) (Figure 5).

Among all countries, the lowest prevalence $[2.0 \%$ (95\% CI: $0.2 \%, 15.7 \%)$ with a $p$ value of $=0.001]$ of Salmonella in 


\begin{tabular}{|c|c|c|c|c|c|c|c|c|c|}
\hline \multirow[b]{2}{*}{$\begin{array}{l}\text { Group b } \\
\text { year }\end{array}$} & \multirow[b]{2}{*}{ Study name } & \multicolumn{5}{|c|}{ Statistics for each study } & \multirow{2}{*}{\multicolumn{3}{|c|}{ Event rate and 95\% CI }} \\
\hline & & $\begin{array}{l}\text { Event } \\
\text { rate }\end{array}$ & $\begin{array}{l}\text { Lower } \\
\text { limit }\end{array}$ & $\begin{array}{l}\text { Upper } \\
\text { limit }\end{array}$ & \multicolumn{2}{|c|}{ Z-value p-value } & & & \\
\hline 2015 & Reddi et al. & 0.426 & 0.349 & 0.506 & -1.806 & 0.071 & & $=$ & \\
\hline 2015 & Elhag et al. & 0.267 & 0.140 & 0.450 & -2.447 & 0.014 & & & \\
\hline 2015 & & 0.365 & 0.227 & 0.529 & -1.622 & 0.105 & & & \\
\hline 2016 & Temesgen et al. & 0.296 & 0.202 & 0.412 & -3.333 & 0.001 & & & \\
\hline 2016 & Ire and Imuh & 0.969 & 0.650 & 0.998 & 2.390 & 0.017 & & & \\
\hline 2016 & Okechukwu et al. & 0.833 & 0.582 & 0.947 & 2.471 & 0.013 & & & \\
\hline 2016 & & 0.751 & 0.222 & 0.970 & 0.919 & 0.358 & & & \\
\hline 2018 & Asghar et al. & 0.300 & 0.179 & 0.457 & -2.456 & 0.014 & & & \\
\hline 2018 & & 0.300 & 0.179 & 0.457 & -2.456 & 0.014 & & & \\
\hline 2019 & Shiningeni et al. & 0.350 & 0.261 & 0.450 & -2.893 & 0.004 & & & \\
\hline 2019 & & 0.350 & 0.261 & 0.450 & -2.893 & 0.004 & & & \\
\hline 2020 & Asiegbu et al. & 0.018 & 0.007 & 0.049 & -7.613 & 0.000 & & & \\
\hline 2020 & & 0.018 & 0.007 & 0.049 & -7.613 & 0.000 & & & \\
\hline Overal & & 0.288 & 0.231 & 0.352 & -5.956 & 0.000 & & $\Delta$ & \\
\hline Rando & m model & & & & & -1.00 & -0.50 & 0.50 & 1.00 \\
\hline
\end{tabular}

FiguRE 4: Subgroup analysis of the pooled prevalence of E. coli in ready-to-eat foods in developing countries by the year of publication, 2020.

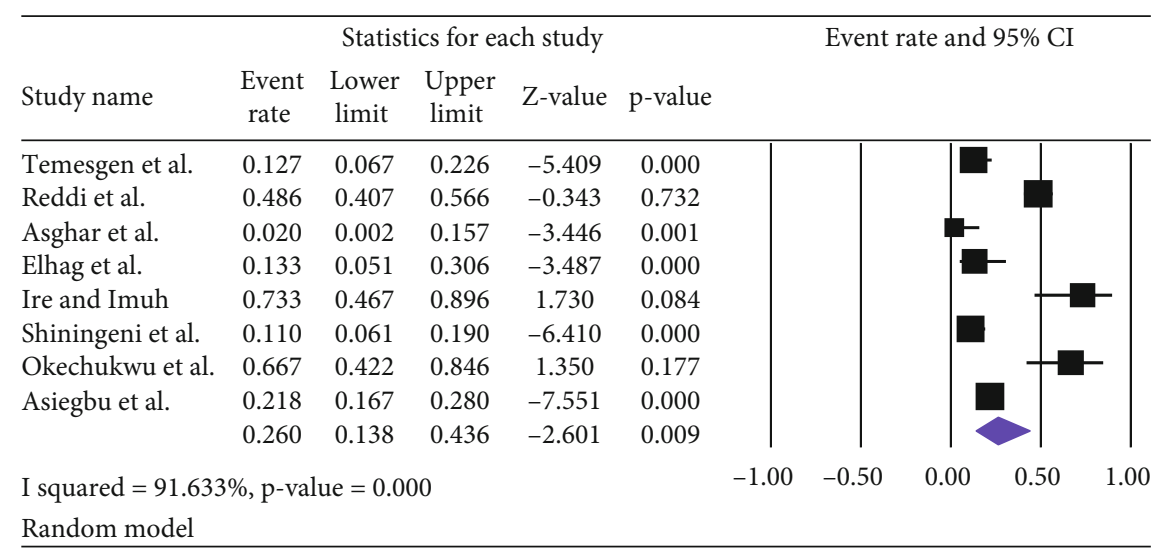

FIGURE 5: The pooled prevalence of Salmonella in ready-to-eat foods in developing countries, 2020.

ready-to-eat foods was observed in Pakistan whereas the highest prevalence [69.7\%, (95\% CI: $51.9-83.0 \%)$ with a $p$ value of 0.031] of Salmonella in ready-to-eat foods was observed in Nigeria. After subgroup analysis, the overall pooled prevalence of Salmonella was found to be [30.0\% (95\% CI: 26.0-34.2\%) with $p$ value of $<0.001$ ] (Figure 6).

Subgroup analysis based on publication year and prevalence of Salmonella among ready-to-eat foods was done. The higher pooled prevalence of Salmonella [47.2\% (95\% CI: 10.6-87.1\%)] was found among those articles published in 2016, whereas the article conducted in 2018 reported lower [2.0\% (95\% CI: $0.2 \%, 15.7 \%)$ with $p$ value of $=0.001]$ prevalence (Figure 7).

(3) Prevalence of Staphylococcus Aureus. The pooled prevalence of Staphylococcus aureus in ready-to-eat foods of developing countries was found to be $46.3 \%$ (95\% CI: $24.8,69.4 \%$, $\left.I^{2}=94.9 \%\right)$ (Figure 8).

A subgroup analysis was performed based on the countries where the articles were conducted and the year of pub- lication. Among the included countries, the lowest prevalence [7\% (95\% CI: 3.3\%, 14.2\%) with a $p$ value of $<$ 0.001] of Staphylococcus aureus in ready-to-eat foods was observed in Namibia whereas the highest prevalence [85\%, (95\% CI: 29.5-98.7\%)] of Staphylococcus aureus in readyto-eat foods was observed in Nigeria. However, after subgroup analysis, the overall prevalence of Staphylococcus aureus was found to be [44.0\% (95\% CI: 39.3 , to $48.8 \%$ ) with a $p$ value of $<0.014$ ] prevalence (Figure 9).

Subgroup analysis based on the publication year of included articles found the lower pooled prevalence of Staphylococcus aureus [7.0\% (95\% CI: 3.3\%, 14.2\%) with $p$ value of $<0.001$ ] among studies published in 2019, while the article published in 2018 reported higher prevalence [70.0\% (95\% CI: $54.3 \%, 82.1 \%)$ with $p$ value of $=0.014$ ] (Figure 10).

\section{Discussion}

Various studies conducted across the world are strongly agreeing with the fact that most of the pathogenic 


\begin{tabular}{|c|c|c|c|c|c|c|c|c|c|}
\hline \multirow[b]{2}{*}{$\begin{array}{l}\text { Group by } \\
\text { study area }\end{array}$} & \multirow[b]{2}{*}{ Study name } & \multicolumn{5}{|c|}{ Statistics for each study } & \multicolumn{3}{|c|}{ Event rate and $95 \% \mathrm{CI}$} \\
\hline & & $\begin{array}{l}\text { Event } \\
\text { rate }\end{array}$ & $\begin{array}{l}\text { Lower } \\
\text { limit }\end{array}$ & $\begin{array}{l}\text { Upper } \\
\text { limit }\end{array}$ & Z-value & $\mathrm{p}$-value & & & \\
\hline Ethiopia & Temesgen et al. & 0.127 & 0.067 & 0.226 & -5.409 & 0.000 & & & \\
\hline Ethiopia & & 0.127 & 0.067 & 0.226 & -5.409 & 0.000 & & & \\
\hline India & Reddi et al. & 0.486 & 0.407 & 0.566 & -0.343 & 0.732 & & & \\
\hline India & & 0.486 & 0.407 & 0.566 & -0.343 & 0.732 & & & \\
\hline Namibia & Shiningeni et al. & 0.110 & 0.061 & 0.190 & -6.410 & 0.000 & & & \\
\hline Namibia & & 0.110 & 0.061 & 0.190 & -6.410 & 0.000 & & & \\
\hline Nigeria & Ire and Imuh & 0.733 & 0.467 & 0.896 & 1.730 & 0.084 & & & \\
\hline Nigeria & Okechukwu et al. & 0.667 & 0.422 & 0.846 & 1.350 & 0.177 & & & \\
\hline Nigeria & & 0.697 & 0.519 & 0.830 & 2.157 & 0.031 & & & \\
\hline Pakistan & Asghar et al. & 0.020 & 0.002 & 0.157 & -3.446 & 0.001 & & & \\
\hline Pakistan & & 0.020 & 0.002 & 0.157 & -3.446 & 0.001 & & & \\
\hline South Africa & ca Asiegbu et al. & 0.218 & 0.167 & 0.280 & -7.551 & 0.000 & & & \\
\hline South Africa & & 0.218 & 0.167 & 0.280 & -7.551 & 0.000 & & & \\
\hline Sudan & Elhag et al. & 0.133 & 0.051 & 0.306 & -3.487 & 0.000 & & & \\
\hline Sudan & & 0.133 & 0.051 & 0.306 & -3.487 & 0.000 & & & \\
\hline Overall & & 0.300 & 0.260 & 0.342 & -8.524 & $0.000 \quad$ & & $\checkmark 1$ & \\
\hline Random mo & odel & & & & & -1.00 & -0.50 & 0.00 & 1.00 \\
\hline
\end{tabular}

FIGURE 6: Subgroup analysis of the pooled prevalence of Salmonella in ready-to-eat foods in developing countries by countries, 2020.

\begin{tabular}{|c|c|c|c|c|c|c|c|c|c|}
\hline \multirow[b]{2}{*}{$\begin{array}{l}\text { Group by } \\
\text { year }\end{array}$} & \multirow[b]{2}{*}{ Study name } & \multicolumn{5}{|c|}{ Statistics for each study } & \multicolumn{3}{|c|}{ Event rate and 95\% CI } \\
\hline & & $\begin{array}{l}\text { Event } \\
\text { rate }\end{array}$ & $\begin{array}{l}\text { Lower } \\
\text { limit }\end{array}$ & $\begin{array}{l}\text { Upper } \\
\text { limit }\end{array}$ & Z-value & p-value & & & \\
\hline 2015 & Reddi et al. & 0.486 & 0.407 & 0.566 & -0.343 & 0.732 & & & \\
\hline 2015 & Elhag et al. & 0.133 & 0.051 & 0.306 & -3.487 & 0.000 & & & \\
\hline 2015 & & 0.290 & 0.065 & 0.708 & -0.985 & 0.324 & & & \\
\hline 2016 & Temesgen et al. & 0.127 & 0.067 & 0.226 & -5.409 & 0.000 & & & \\
\hline 2016 & Ire and Imuh & 0.733 & 0.467 & 0.896 & 1.730 & 0.084 & & & \\
\hline 2016 & Okechukwu et al. & 0.667 & 0.422 & 0.846 & 1.350 & 0.177 & & & \\
\hline 2016 & & 0.472 & 0.106 & 0.871 & -0.107 & 0.915 & & & \\
\hline 2018 & Asghar et al. & 0.020 & 0.002 & 0.157 & -3.446 & 0.001 & & & \\
\hline 2018 & & 0.020 & 0.002 & 0.157 & -3.446 & 0.001 & & & \\
\hline 2019 & Shiningeni et al. & 0.110 & 0.061 & 0.190 & -6.410 & 0.000 & & & \\
\hline 2019 & & 0.110 & 0.061 & 0.190 & -6.410 & 0.000 & & 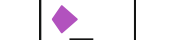 & \\
\hline 2020 & Asiegbu et al. & 0.218 & 0.167 & 0.280 & -7.551 & 0.000 & & & \\
\hline 2020 & & 0.218 & 0.167 & 0.280 & -7.551 & 0.000 & & 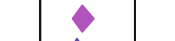 & \\
\hline Overall & & 0.190 & 0.150 & 0.238 & -9.966 & 0.000 & & 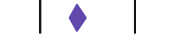 & \\
\hline \multicolumn{2}{|c|}{ Random model } & & & & & -1.00 & -0.50 & 0.00 & 1.00 \\
\hline
\end{tabular}

Figure 7: Subgroup analysis of the pooled prevalence of Salmonella in ready-to-eat foods in developing countries by the year of publication, 2020.

\begin{tabular}{|c|c|c|c|c|c|c|c|c|c|}
\hline \multirow[b]{2}{*}{ Study name } & \multicolumn{5}{|c|}{ Statistics for each study } & \multicolumn{4}{|c|}{ Event rate and $95 \% \mathrm{CI}$} \\
\hline & $\begin{array}{c}\text { Event } \\
\text { rate }\end{array}$ & $\begin{array}{l}\text { Lower } \\
\text { limit }\end{array}$ & $\begin{array}{l}\text { Upper } \\
\text { limit }\end{array}$ & Z-value & $\mathrm{p}$-value & & & & \\
\hline Temesgen et al. & 0.099 & 0.048 & 0.193 & -5.558 & 0.000 & & & & \\
\hline Reddi et al. & 0.733 & 0.657 & 0.798 & 5.472 & 0.000 & & & & \\
\hline Asghar et al. & 0.700 & 0.543 & 0.821 & 2.456 & 0.014 & & & & \\
\hline Elhag et al. & 0.550 & 0.373 & 0.715 & 0.547 & 0.585 & & & & \\
\hline Ire and Imuh & 0.969 & 0.650 & 0.998 & 2.390 & 0.017 & & & & \\
\hline Shiningeni et al. & 0.070 & 0.033 & 0.142 & -6.467 & 0.000 & & & & \\
\hline Okechukwu et al. & 0.667 & 0.422 & 0.846 & 1.350 & 0.177 & & & & \\
\hline \multirow[t]{2}{*}{ Asiegbu et al. } & 0.318 & 0.258 & 0.385 & -5.087 & 0.000 & & & & \\
\hline & 0.463 & 0.248 & 0.694 & -0.299 & 0.765 & & & & \\
\hline \multicolumn{6}{|c|}{ I squared $=94.929 \%, \mathrm{p}$-value $=0.000$} & -1.00 & -0.50 & 0.00 & 1.00 \\
\hline
\end{tabular}

FIGURE 8: The pooled prevalence of Staphylococcus aureus in ready-to-eat foods in developing countries, 2020. 


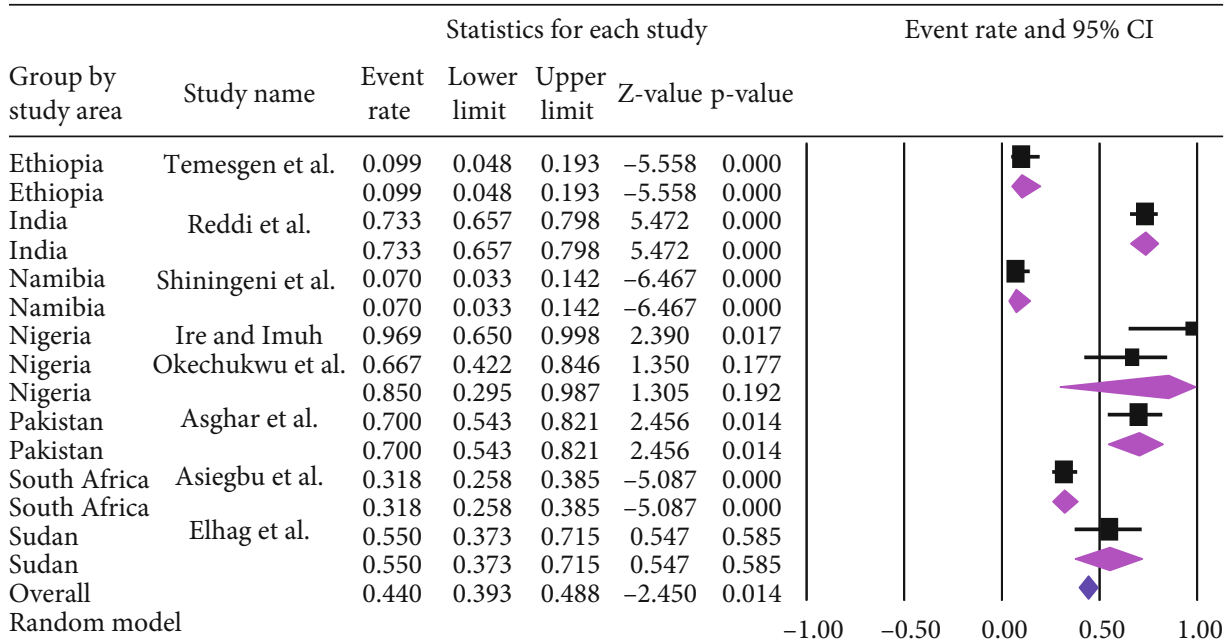

FIGURE 9: Subgroup analysis of the pooled prevalence of Staphylococcus aureus in ready-to-eat foods in developing countries by countries, 2020.

\begin{tabular}{|c|c|c|c|c|c|c|c|c|c|}
\hline \multirow[b]{2}{*}{$\begin{array}{l}\text { Group by } \\
\text { year }\end{array}$} & \multirow[b]{2}{*}{ Study name } & \multicolumn{5}{|c|}{ Statistics for each study } & \multicolumn{3}{|c|}{ Event rate and $95 \% \mathrm{CI}$} \\
\hline & & $\begin{array}{l}\text { Event } \\
\text { rate }\end{array}$ & $\begin{array}{l}\text { Lower } \\
\text { limit }\end{array}$ & $\begin{array}{l}\text { Upper } \\
\text { limit }\end{array}$ & Z-value & $\mathrm{p}$-value & & & \\
\hline 2015 & Reddi et al. & 0.733 & 0.657 & 0.798 & 5.472 & 0.000 & & & \\
\hline 2015 & Elhag et al. & 0.550 & 0.373 & 0.715 & 0.547 & 0.585 & & & \\
\hline 2015 & & 0.661 & 0.471 & 0.810 & 1.669 & 0.095 & & & \\
\hline 2016 & Temesgen et al. & 0.099 & 0.048 & 0.193 & -5.558 & 0.000 & & $=$ & \\
\hline 2016 & Ire and Imuh & 0.969 & 0.650 & 0.998 & 2.390 & 0.017 & & & \\
\hline 2016 & Okechukwu et al. & 0.667 & 0.422 & 0.846 & 1.350 & 0.177 & & & \\
\hline 2016 & & 0.590 & 0.087 & 0.956 & 0.262 & 0.793 & & & \\
\hline 2018 & Asghar et al. & 0.700 & 0.543 & 0.821 & 2.456 & 0.014 & & & \\
\hline 2018 & & 0.700 & 0.543 & 0.821 & 2.456 & 0.014 & & & \\
\hline 2019 & Shiningeni et al. & 0.070 & 0.033 & 0.142 & -6.467 & 0.000 & & & \\
\hline 2019 & & 0.070 & 0.033 & 0.142 & -6.467 & 0.000 & & $\bullet$ & \\
\hline 2020 & Asiegbu et al. & 0.318 & 0.258 & 0.385 & -5.087 & 0.000 & & & \\
\hline 2020 & & 0.318 & 0.258 & 0.385 & -5.087 & 0.000 & & 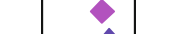 & \\
\hline Overall & & 0.358 & 0.304 & 0.415 & -4.756 & 0.000 & & $\bullet$ & \\
\hline \multicolumn{2}{|c|}{ Random model } & & & & & -1.00 & -0.50 & 0.00 & 1.00 \\
\hline
\end{tabular}

FIGURE 10: Subgroup analysis of the pooled prevalence of Staphylococcus aureus in ready-to-eat foods in developing countries by the year of publication, 2020.

microorganisms of public health concerns are introduced to foods during handling, processing, and preparation [25]. These microorganisms have potential health risks to consumers, particularly in developing countries, and need to be addressed to protect the health and wellbeing of the public.

Among 8 articles included in this review, Ire and Imuh 2016 reported a higher prevalence of $E$. coli and S. aureus than other included articles, while Asiegbu et al., 2020, reported lower E. coli. However, the highest and lowest prevalence of Salmonella was reported by Ire and Imuh, 2016, and Asghar et al., 2018, respectively (Figure 11).

The difference in microorganisms may be related to poor hygiene and safety practices or due to contamination of raw materials used or water supply used or the lifestyle of the community where the study was conducted.

The current review found the overall prevalence of positive ready-to-eat foods in terms of E. coli, Salmonella, and S. aureus that accounts for 172 (27.5\%), 168 (26.9\%), and 259 (41.4\%), respectively. However, quantitative analysis of the included articles indicated the pooled prevalence of Escherichia coli in ready-to-eat foods accounts 33.8\%, while the pooled prevalence of Salmonella and Staphylococcus accounts for $26.0 \%$ and $46.3 \%$, respectively. Another quantitative analysis (meta-analysis) conducted in selected African countries was agreed with the current finding in terms of pooled prevalence of $E$. coli (31.6\%). However, found lower pooled prevalence of Salmonella (21.7\%) and Staphylococcus aureus $(25.1 \%)$ among ready to eat foods than the current finding [26]. The variation may be due to poor hygiene, safety and sanitation conditions, low quality of raw materials used, lack or inadequate training on food hygiene, and safety for food handlers.

\section{Conclusion}

This systematic review and meta-analysis estimated the pooled prevalence of E. coli, Salmonella, and Staphylococcus aureus in ready-to-eat foods in developing countries. The 


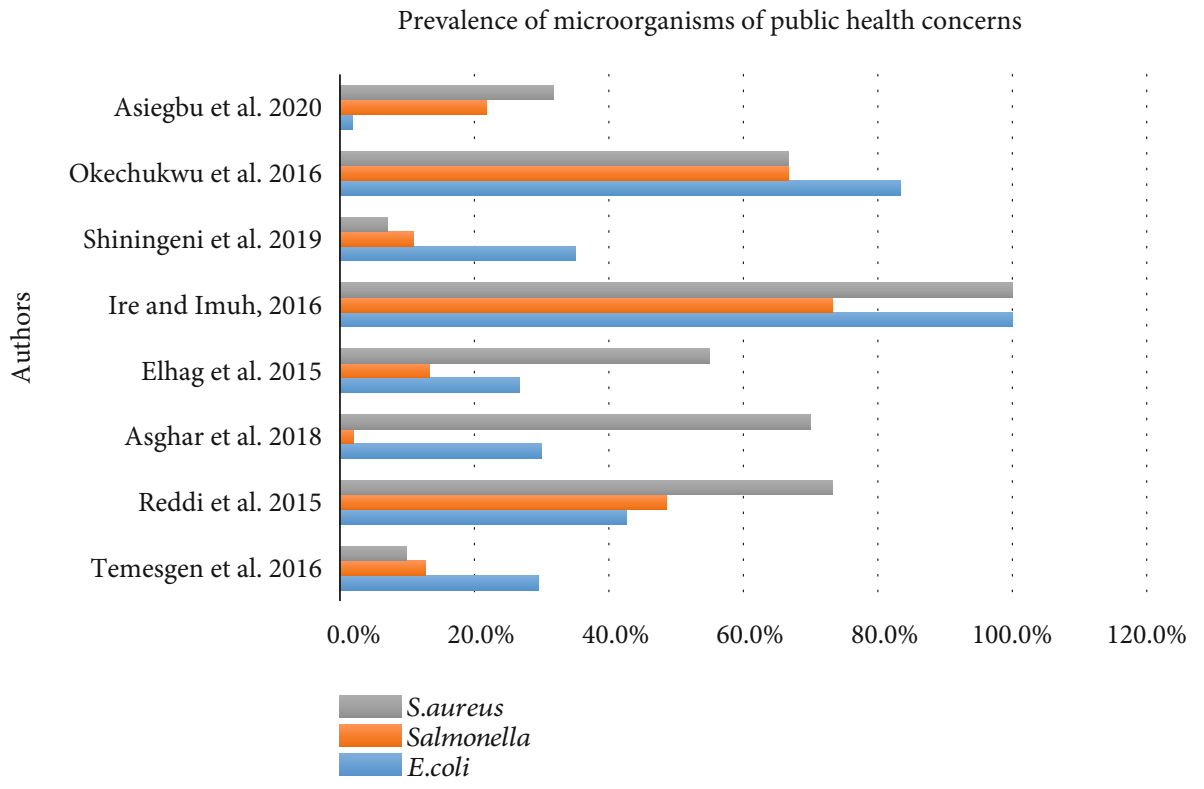

Figure 11: Show the reported prevalence of E. coli, Salmonella, and Staphylococcus in ready-to-eat foods in developing countries.

findings show that contamination of ready-to-eat foods with pathogenic microorganisms continues to be a public health risk that needs to be addressed to protect the health and wellbeing of the consumers and the public as a whole. Thus, effective food hygiene and safety systems and tailor training both at the national and international level are necessary to prevent foodborne illness/disease and to protect the health of the consumers and the public as a whole.

\section{Abbreviations}

CMA: Comprehensive Meta-Analysis

JBI: Joanna Briggs Institute

PRISMA: Preferred Reporting Items for Systematic Review and Meta-Analysis

RTE: $\quad$ Ready to eat

WHO: World Health Organization.

\section{Data Availability}

All data are included in the systematic review and metaanalysis. In addition, the Supplementary materials including PRISMA-P (Preferred Reporting Items for Systematic Review and Meta-Analysis Protocols) 2015 checklist are the recommended items to address in a systematic review protocol.

\section{Conflicts of Interest}

The authors declare that they have no conflicts of interest.

\section{Authors' Contributions}

Dechasa Adare Mengistu conceived the idea and had major roles in the data review, extraction, and analysis. Sina Temesgen Tolera had a role in data extraction too. Both authors
(Mengistu DA and Tolera ST) have contributed in analysis, writing, drafting, and editing. Finally, the authors (Mengistu DA and Tolera ST) read and approved the final version to be published and agreed on all aspects of this work.

\section{Supplementary Materials}

PRISMA-P (Preferred Reporting Items for Systematic Review and Meta-Analysis) 2015 checklist is one of the recommended items to address in a systematic review. (Supplementary Materials)

\section{References}

[1] D. Tsang, "Microbiological guidelines for ready to eat food Road and Environmental Hygiene Department," Hong Kong, pp. 115-116, 2002.

[2] World Health Organization, WHO, "Programme for Control of Diarrhoeal Diseases. Manual for Laboratory Investigations of Acute Enteric Infections," CDD/83.3, Review 1. Geneva, 2002.

[3] J. N. P. Adolf and B. S. Azis, "Microbiological status of various foods served in elementary school based on social-economic status differences in Karawachi Region," International Food Research Journal, vol. 19, no. 1, pp. 65-70, 2012.

[4] B. A. Alimi, "Risk factors in street food practices in developing countries. A review," Food Science and Human Wellness, vol. 5, no. 3, pp. 141-148, 2016.

[5] A. Atter, H. Ofori, G. A. Anyebuno, M. Amoo-Gyasi, and W. K. Amoa-Awua, "Safety of a street vended traditional maize beverage, ice-kenkey, in Ghana," Food Control, vol. 55, pp. 200-205, 2015.

[6] L. S. Manguiat and T. J. Fang, "Microbiological quality of chicken and pork-based street vended foods," International Journal of Microbiology, vol. 36, 62 pages, 2013. 
[7] WHO/FAO, "Assuring Food Safety and Quality: Guidelines for Strengthening National Food Control Systems," Food and Nutrition Paper, no. 76, 2015.

[8] T. Rahman, S. Hasan, and R. Noor, "An assessment of microbiological quality of some commercially packed and fresh fruit juice available in Dhaka city: A comparative study," Stamford Journal of Microbiology, vol. 1, no. 1, pp. 13-18, 2011.

[9] WHO, "Food Safety and Nutrition during Pregnancy and Infant Feeding," INFOSAN Information Note, no. 3, 2008.

[10] R. De Vogli, A. Kouvonen, and D. Gimeno, "The influence of market deregulation on fast food consumption and body mass index: a cross-national time-series analysis," Bulletin of the World Health Organization, vol. 92, no. 99, p. 107, 2014.

[11] WHO, "WHO's first-ever global estimates of foodborne diseases," http://journals.plos.org/plosmedicine/article?id=10 $.1371 /$ journal?.

[12] G. Andargie, A. Kassu, F. Moges, M. Tiruneh, and K. Huruy, "Prevalence of bacteria and intestinal parasites among food handlers in Gondar town, northwest Ethiopia," Journal of Health, Population and Nutrition, vol. 26, pp. 451-454, 2009.

[13] WHO, 10 Facts on Food Safety2015, http://www.who.int/ features/factfiles/food_safety/facts/en/index.html.

[14] J. C. Heaton and K. Jones, "Microbial contamination of fruit and vegetables and behavior of enteropathogens in the phyllosphere: a review," Journal of Applied Microbiology, vol. 104, pp. 613-626, 2008.

[15] PRISMA-P Group, D. Moher, L. Shamseer et al., "Preferred reporting items for systematic review and meta-analysis protocols (PRISMA-P) 2015 statement," Systematic Reviews, vol. 4, no. $1,2015$.

[16] The Joanna Briggs Institute, Critical appraisal tools for use in the JBI systematic reviews checklist for prevalence studies, The University of Adelaide, 2016, https://joannabriggs.org/sites/ default/files/2019-05/JBI_Critical_Appraisal Checklist_for_ Prevalence_Studies2017_0.pdf.

[17] T. Eromo, H. Tassew, D. Daka, and G. Kibru, "Bacteriological quality of street foods and antimicrobial resistance of isolates in Hawassa," Ethiopia, Ethiopian Journal of Health Sciences, vol. 26, no. 6, pp. 533-542.

[18] S. G. Reddi, R. N. Kumar, N. Balakrishna, and V. S. Rao, "Microbiological quality of street vended fruit juices in Hyderabad, India, and their association between food safety knowledge and practices of fruit juice vendors," International Journal of Current Microbiology and Applied Sciences, vol. 4, no. 1, pp. 970-982, 2015.

[19] U. Asghar, M. Nadeem, R. Nelofer, S. Mazhar, Q. Syed, and M. Irfan, "Microbiological assessment of fresh juices vended in different areas of Lahore City," Electronic Journal Biology, vol. 14 , no. 4 .

[20] N. B. Elhag, M. J. Remaz, and E. R. B. Babiker, "Characterization of some pathogenic bacteria associated with fresh juices sold in the central bus station at Khartoum State," Sudan. International Journal of Science and Research (IJSR), vol. 6, no. 6, pp. 1351-1359, 2017.

[21] F. Ire and V. Imuh, "Bacteriological quality evaluation and safety of randomly selected ready-to-eat foods sold in Port Harcourt City, Nigeria," Journal of Applied Life Sciences International, vol. 7, no. 1, pp. 1-10, 2016.

[22] D. Shiningeni, P. Chimwamurombe, R. Shilangale, and J. Misihairabgwi, "Prevalence of pathogenic bacteria in street vended ready-to-eat meats in Windhoek, Namibia," Meat Science, vol. 148, pp. 223-228, 2019.

[23] O. J. Okechukwu, I. Orinya Chinedu, O. Okonkwo Eucharia et al., "The microbial contamination of ready-to-eat vended fruits in Abakpa Main Market, Abakaliki, Ebonyi State, Nigeria," IOSR Journal of Pharmacy and Biological Sciences, vol. 11, no. 6, pp. 71-80, 2016.

[24] C. V. Asiegbu, S. L. Lebelo, and F. T. Tabit, "Microbial quality of ready-to-eat street vended food groups sold in the Johannesburg Metropolis, South Africa," Journal of Food Quality and Hazards Control, vol. 7, pp. 18-26, 2020.

[25] S. Rane, "Street vended food in developing world: hazard analyses," Indian Journal of Microbiology, vol. 51, no. 1, pp. 100106, 2011.

[26] N. Paudyal, V. Anihouvi, J. Hounhouigan et al., "Prevalence of foodborne pathogens in food from selected African countriesa meta-analysis," International Journal of Food Microbiology, vol. 249, pp. 35-43, 2017. 